\title{
Risk and Protective Factors for COVID-19 Morbidity, Severity, and Mortality
}

\author{
Jin-jin Zhang ${ }^{1,2} \cdot$ Xiang Dong $^{1,2} \cdot$ Guang-hui Liu ${ }^{1,2} \cdot$ Ya-dong Gao ${ }^{1,2}$ \\ Accepted: 6 January 2022 / Published online: 19 January 2022 \\ (c) The Author(s), under exclusive licence to Springer Science+Business Media, LLC, part of Springer Nature 2022
}

\begin{abstract}
The outbreak of the coronavirus disease 2019 (COVID-19), caused by the novel severe acute respiratory syndrome coronavirus 2 (SARS-CoV-2), has become an evolving global health crisis. Currently, a number of risk factors have been identified to have a potential impact on increasing the morbidity of COVID-19 in adults, including old age, male sex, pre-existing comorbidities, and racial/ethnic disparities. In addition to these factors, changes in laboratory indices and pro-inflammatory cytokines, as well as possible complications, could indicate the progression of COVID-19 into a severe and critical stage. Children predominantly suffer from mild illnesses due to COVID-19. Similar to adults, the main risk factors in pediatric patients include age and pre-existing comorbidities. In contrast, supplementation with a healthy diet and sufficient nutrition, COVID-19 vaccination, and atopic conditions may act as protective factors against the infection of SARS-CoV-2. COVID19 vaccination not only protects vulnerable individuals from SARS-CoV-2 infection, more importantly, it may also reduce the development of severe disease and death due to COVID-19. Currently used therapies for COVID-19 are off-label and empiric, and their impacts on the severity and mortality of COVID-19 are still unclear. The interaction between asthma and COVID-19 may be bidirectional and needs to be clarified in more studies. In this review, we highlight the clinical evidence supporting the rationale for the risk and protective factors for the morbidity, severity, and mortality of COVID-19.
\end{abstract}

Keywords COVID-19 $\cdot$ SARS-CoV-2 $\cdot$ Risk factors $\cdot$ Protective factors $\cdot$ Comorbidity $\cdot$ Asthma

\section{Introduction}

The coronavirus disease 2019 (COVID-19) pandemic, caused by severe acute respiratory syndrome coronavirus 2 (SARS-CoV-2), has led to high morbidity and mortality worldwide. As of December 19, 2021, COVID-19 has affected more than 273 million people and has led to the death of over 5.3 million [1]. SARS-CoV-2 infection may remain asymptomatic in the early stages, until the emergence of severe pneumonia, dyspnea, organ dysfunction, and even death [2]. Although all ages can be affected, the infection has a lower clinical impact on children than on adults. Most infected children appear to have a milder course and better clinical outcomes. As the COVID-19 pandemic evolved,

Ya-dong Gao

gaoyadong@whu.edu.cn

1 Department of Allergology, Zhongnan Hospital of Wuhan University, Donghu Road 169, Wuhan 430071, Hubei, China

2 Hubei Province Key Laboratory of Allergy and Immunology, Wuhan University, Wuhan 430071, Hubei, China infections, hospitalizations, and deaths have varied among and within countries and regions worldwide, prompting questions about risk and protective factors for COVID-19.

With millions of confirmed cases worldwide, a comprehensive understanding of the risk and protective factors for COVID-19 will be helpful for the prevention of disease infection, progression, and adverse outcomes in infected patients. Based on current evidence, risk factors for developing COVID-19 in adults range from demographic factors, such as older age, male sex, and ethnicity, to the presence of underlying diseases such as cardiovascular diseases, hypertension, and chronic obstructive pulmonary disease (COPD) [3]. Similarly, it has been reported that younger children and specific comorbidities such as obesity are at higher risk for infection and potentially more severe consequences of COVID-19 [4-7]. In addition to these factors, the major risk factors for the severity and mortality of COVID-19 also include laboratory indices, pro-inflammatory cytokine levels, and complications [8-11]. In contrast, healthy diet/ nutrition, COVID-19 vaccine, and atopic conditions may protect us from the disease and avoid progression and 
poor clinical outcome [12-14] (Fig. 1). The role of current therapeutic treatments for COVID-19 and asthma is still under debate. Important questions remain regarding the underlying mechanisms. In this review, we summarize the current information on the risk factors and protective factors for morbidity and severity/mortality of COVID-19 in adults and children. The correlations and potential mechanisms of risk factors and protective factors against COVID-19 in adults and children are summarized in Tables 1 and 2.

\section{Risk Factors for Susceptibility to COVID-19 in Adults}

\section{Older Age}

As a vulnerable population group with decreased efficacy of the immune system, elderly people tend to have higher odds of developing infectious diseases [15]. A meta-analysis of 59 studies comprising 36,470 patients showed that patients aged $70+$ appear to have a $65 \%$ higher risk for COVID-19 (RR: $1.65,95 \%$ CI: 1.50 to 1.81 ) [16]. The epidemic data from China, Italy, Japan, Singapore, Canada, and South Korea showed an age-dependent disparity in susceptibility to COVID-19. Age dependence in susceptibility to COVID19 was markedly lower in younger age groups in all regions, from $21 \%$ in those aged $10-19$ years to $69 \%$ in those aged over 70 years. The relative susceptibility to infection was $0.40(0.25-0.57)$ in children aged $0-9$ years, compared with $0.88(0.70-0.99)$ in those aged 60-69 years [17]. Similarly, in another study examining SARS-CoV-2 epidemiology in China, compared to the susceptibility in individuals aged 60-69 years, the relative susceptibility was 0.06 in children and adolescents aged $0-19$ years, 0.34 in adults aged 20-29 years, 0.57 in adults aged $30-39$ years, 0.69 in those aged $40-49$ years, 0.79 in individuals aged $50-59$ years, 0.94 in elderly individuals aged 70-79 years, and 0.88 in individuals aged $\geq 80$ years [18]. This evidence proved that age may be a risk factor in the epidemiology of this infection.

Elderly individuals often have more comorbidities. In addition, weaker immune defense against infectious diseases and

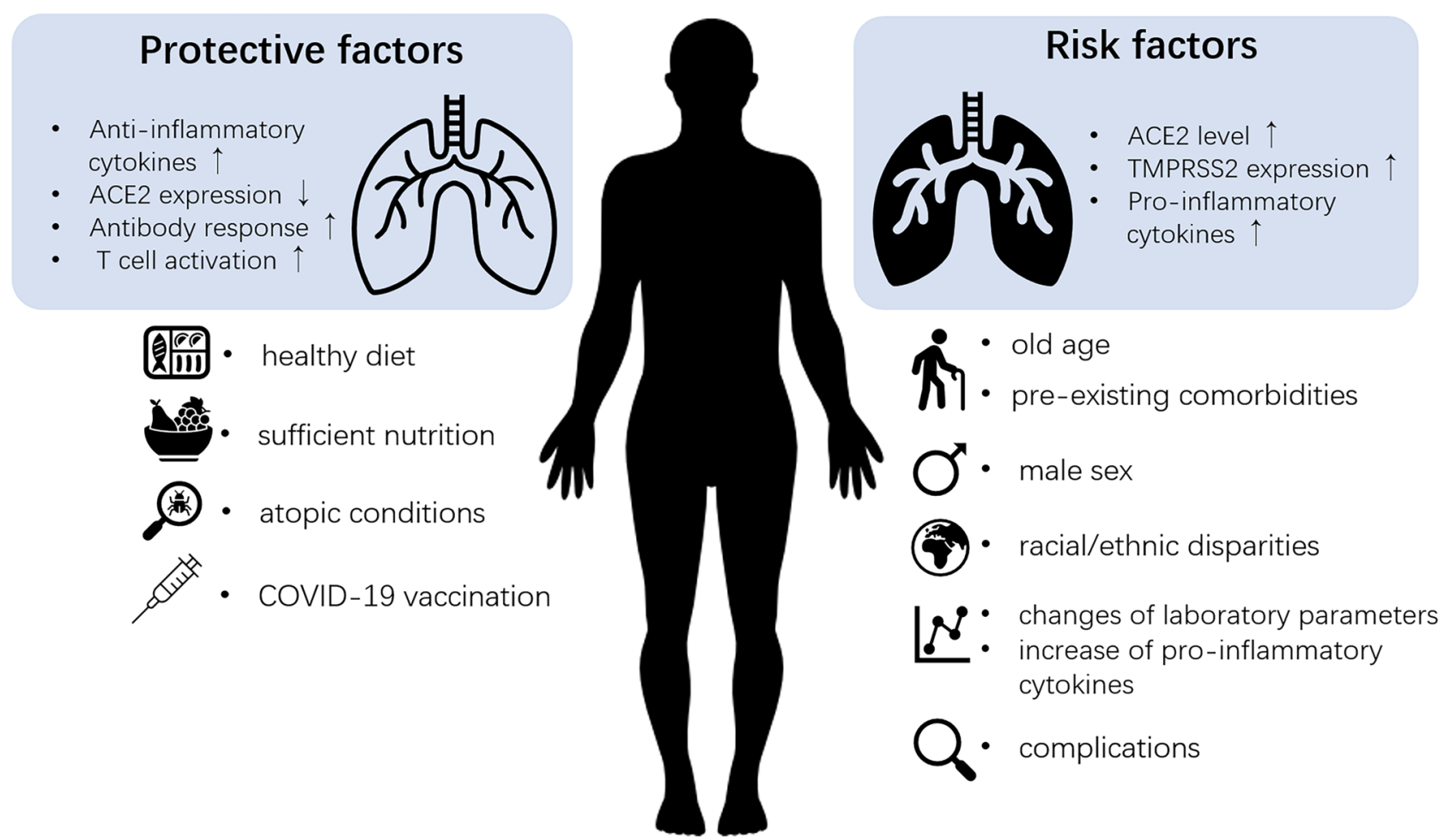

Fig. 1 Part of the protective and risk factors of COVID-19. Healthy diet, sufficient nutrition, atopic conditions, and COVID-19 vaccination are protective factors against the infection and development of COVID19. Increased anti-inflammatory cytokines and decreased ACE2 expression may contribute to the protective effect of these factors. Also, induction of antibody response and T-cell activation by COVID-19 vaccination may also help in avoiding the infection, progression, and poor clinical outcome. On the contrary, old age, male sex, pre-existing comorbidities, and racial/ethnic disparities are risk factors for the morbidity of COVID-19. In addition, increases in the several laboratory indices and pro-inflammatory cytokines, as well as possible complications, could indicate the progression of COVID-19 into a severe and critical stage. Elevated expression of ACE2 and TMPRSS2, as well as the increase of pro-inflammatory cytokines, may underlie the predisposition. ACE2, angiotensin-converting enzyme; TMPRSS2, transmembrane protease serine 2 
Table 1 Risk and protecting factors and their correlations with the infection and severity of COVID-19 in adults

\begin{tabular}{|c|c|}
\hline Risk factors for COVID-19 infection & Correlations \\
\hline Older age & $\begin{array}{l}\text { - Weaker immune defense against infectious pathogens [19] } \\
\text { - Associated with more comorbidities [19] } \\
\text { - Aging-related chronic pro-inflammatory status of the immune system with persistent low-grade } \\
\text { innate immune activation [8] }\end{array}$ \\
\hline Male sex & $\begin{array}{l}\text { - Weaker immunity due to genetic and hormonal factors [8] } \\
\text { - Normal serum testosterone level may foster viral entry into host cells and facilitate systemic } \\
\text { dissemination of SARS-CoV-2 [20,21] } \\
\text { - Lifestyle that predisposes to infection (such as smoking) [8] } \\
\text { - Higher levels of ACE2 on the endothelium of the pulmonary vessels [19] }\end{array}$ \\
\hline Pre-existing comorbidities & $\begin{array}{l}\text { - Weaker immune defense [19] } \\
\text { - Pro-inflammatory status of the immune system [19] }\end{array}$ \\
\hline Racial/ethnic disparities & $\begin{array}{l}\text { - Difference in the essential workforce services, poverty, access to healthcare, and insurance [22] } \\
\text { - Increase the potential exposure to SARS-CoV-2 and community transmission and delay the time } \\
\text { from symptom onset to hospitalization [22] } \\
\text { - Inequality in healthcare utilization [22] }\end{array}$ \\
\hline Healthcare workers (HCWs) & $\begin{array}{l}\text { - Higher exposed viral load } \\
\text { - Increased viral exposure time }\end{array}$ \\
\hline Protective factors for COVID-19 infection & Correlations \\
\hline Diet and nutrition & $\begin{array}{l}\text { - Cathelicidins and defensins result from the consumption of vitamin D can reduce viral replication } \\
\text { rates and the levels of pro-inflammatory cytokines (e.g., IL-1, IL-6, IL-8, IL-12, and TNF- } \alpha \text { ) [23, 24] } \\
\text { - Adequate vitamin D level may help to protect the respiratory epithelium from pathogenic } \\
\text { invasion [12] } \\
\text { - Vitamin C can help reduce levels of pro-inflammatory cytokines (e.g., TNF- } \alpha \text { and IL-10) [25] }\end{array}$ \\
\hline Vaccines & $\begin{array}{l}\text { - More efficient production of neutralizing antibodies against SARS-CoV-2 at the beginning of } \\
\text { the infection due to the larger number of activated B cells [26] } \\
\text { - More effectively trained and sustained innate immunity [13] }\end{array}$ \\
\hline Atopic conditions & $\begin{array}{l}\text { - Lower expression of ACE2 receptor caused by type } 2 \text { inflammation [27] } \\
\text { - Lower IFN- } \alpha \text { production }[26,28] \\
\text { - Protective role of eosinophils in the airway }[26,28]\end{array}$ \\
\hline $\begin{array}{l}\text { Risk factors for the severity and mortality } \\
\text { of COVID-19 disease progression }\end{array}$ & Correlations \\
\hline Older age & $\begin{array}{l}\text { - High prevalence of comorbidities [8] } \\
\text { - Decreased reserve capacity of vital organs [19] } \\
\text { - Weaker immune defense [8] } \\
\text { - Higher SARS-CoV-2 viral load [8] } \\
\text { - Persistent low-grade innate immune activation [19] } \\
\text { - Higher levels of pro-inflammatory cytokines [8] }\end{array}$ \\
\hline Male sex & $\begin{array}{l}\text { - Lower testosterone levels in aged and comorbid men may lead to male hypogonadism and } \\
\text { induces cardiovascular events, exaggerating immune system, and coagulative response [20] } \\
\text { - Higher frequency of underlying diseases such as type II diabetes and cardiovascular diseases } \\
\text { [29] } \\
\text { - Lower antibody production and delayed viral RNA clearance [29] } \\
\text { - Higher risk of cytokine storm [29] }\end{array}$ \\
\hline Pre-existing comorbidities & $\begin{array}{l}\text { - Sustained low level of immunity status reduces the resistance to virus infection }[8,30] \\
\text { - Previous organ damage promotes the progression of COVID-19 [11] }\end{array}$ \\
\hline Laboratory indices & $\begin{array}{l}\text { - Significantly elevated inflammatory markers suggest a hyperinflammatory state in patients with } \\
\text { severe disease [31] } \\
\text { - May indicate the association with co-infection [31] }\end{array}$ \\
\hline Pro-inflammatory cytokines & $\begin{array}{l}\text { - Significantly higher levels of circulating IL-6, IL-8, IL-10, IL-2R, and TNF- } \alpha \text { in severe cases } \\
\text { [32] } \\
\text { - Cytokine storm can develop a rapid inflammatory signaling cascade and lead to fatality in severe } \\
\text { cases [33] } \\
\text { - Deficiency in IFN-I response [8] }\end{array}$ \\
\hline Complications & $\begin{array}{l}\text { - Hypoxemia, acute respiratory distress syndrome (ARDS), metabolic acidosis, coagulopathy, } \\
\text { and septic shock may cause loss of normal organ function (include hepatic, cardiovascular, and } \\
\text { pulmonary function) [34-36] }\end{array}$ \\
\hline
\end{tabular}


Table 1 (continued)

\begin{tabular}{ll}
\hline Risk factors for COVID-19 infection & Correlations \\
\hline $\begin{array}{l}\text { Protective factors for the severity and } \\
\text { mortality of COVID-19 disease progres- }\end{array}$ & Correlations \\
\begin{tabular}{ll} 
sion & \\
Vaccine & $\bullet$ Induction of neutralizing antibodies [13] \\
& $\bullet$ Establishment of immune memory, including T-cell activation [13] \\
\hline
\end{tabular}
\end{tabular}

aging-related chronic pro-inflammatory status of the immune system with persistent low-grade innate immune activation may increase tissue damage caused by infections in the elderly [19]. In addition, higher levels of pro-inflammatory cytokines with increasing age may contribute to the development of this disease [8].

\section{Male Sex}

Males are predisposed to SARS-CoV-2 infection. Initial pandemic reports from China indicated that men accounted for $\sim 60 \%$ of COVID-19 patients [37, 38]. A meta-analysis of 59 studies comprising 36,470 patients showed that men had a higher risk of infection, disease severity, intensive care unit (ICU) admission, and death than women. Overall, men had a statistically significant $8 \%$ higher risk of being diagnosed with COVID-19 than women (RR: 1.08, 95\% CI: 1.03 to 1.12 ) [16]. In another study, among 4,880 patients with respiratory symptoms or close contact with COVID19 patients, 1,875 (38\%) tested positive for SARS-CoV-2 infection, and the positive percentage was $40.43 \%$ in men, significantly higher than that in women (36.71\%) [39].

It has been suggested that compared to female sex, the different effects of hormones in inflammatory processes, differences in levels of cell receptors (angiotensin-converting enzyme, ACE2) and molecules that facilitate SARS-CoV-2 entry through virus-cell membrane fusion (transmembrane protease serine 2, TMPRSS2), and lifestyle differences (such as smoking) in males may account for the predisposition of males to COVID-19 infection [8].

\section{Pre-existing Comorbidities}

Previous findings have indicated that patients with underlying comorbidities are more vulnerable to COVID-19, as their underlying diseases predispose them to infection. A significant proportion of COVID-19 patients are reported to suffer from other pathophysiological conditions [40]. In the initial cohort of 1,590 COVID-19 patients from China [41], Guan et al. reported that $399(25.1 \%)$ patients had at least one comorbidity, while $130(8.2 \%)$ patients had two or more comorbidities. Hypertension (16.9\%), diabetes (8.2\%), cardiovascular diseases $(3.7 \%)$, and chronic kidney disease $(1.3 \%)$ were the most common comorbidities in all COVID-19 patients. Chen et al. [42] also reported that $51 \%$ (50/99) of COVID-19 patients in their cohort had comorbidities, including cardiovascular or cerebrovascular diseases (40.4\%), diabetes (12\%), digestive system diseases $(11 \%)$, and malignant tumors $(0.01 \%)$.

A study reported that the cardiovascular system may be the main target of SARS-CoV-2, and cardiovascular diseases were the most common comorbidities in all phases of COVID-19 infection [43, 44]. As SARS-CoV-2 infection is capable of inducing endothelial inflammation in various organs due to both viral infection and the host's own immune response [45], patients with cardiovascular disease could be more susceptible to COVID-19 infection.

For patients with cancer, a recent study compared data from both COVID-19 negative and positive cancer patients in the UK [46]. Of the 2,152 cancer patients included in the study, 190 (9\%) were infected with SARS-CoV-2. Patients with hematological cancer were at a higher risk of developing

Table 2 Risk factors and their correlations with the infection and severity of COVID-19 in children

\begin{tabular}{|c|c|}
\hline $\begin{array}{l}\text { Risk factors for the infection and severity of } \\
\text { COVID-19 }\end{array}$ & Correlations \\
\hline Age (infants and/or older adolescents) & $\begin{array}{l}\text { - Immaturity of the immune system [47] } \\
\text { - Lower likelihood of wearing face masks and the subsequent high viral load [47] } \\
\text { - Minimal or lower pre-existing immunity to help protect against severe lower respiratory } \\
\text { illness due to SARS-CoV-2 [48] }\end{array}$ \\
\hline Pre-existing comorbidities & $\begin{array}{l}\text { - Weaker immune defense [5-7] } \\
\text { - Sustained lower level of immunity status reduces the resistance to virus infection }[8,30] \\
\text { - Previous organ damage promotes the progression of COVID-19 [13] }\end{array}$ \\
\hline
\end{tabular}

$A C E 2$ angiotensin-converting enzyme, $I L$ interleukin, $I F N$ interferon, $T N F$ tumor necrosis factor 
COVID-19 than those with solid malignancies. This difference may be due to the impaired SARS-CoV-2-specific antibody response in patients with hematological malignancies, compared to those with solid malignancies [49]. Increased expression of cellular receptors may also account for the higher susceptibility to SARS-CoV-2 infection in patients with comorbidities. Singh et al. [40] recently observed elevated expression of ACE2 in many pathological conditions, such as leukemia, lung cancer, breast cancer, cervical cancer, non-alcoholic fatty liver disease, psoriasis, and pulmonary arterial hypertension. In addition, the level of TMPRSS2 was found to be upregulated in leukemia, lung cancer, and type II diabetes [40].

\section{Racial/Ethnic Disparities}

Many studies have attempted to reveal the different prevalence of COVID-19 among different races and ethnicities. According to a systemic analysis including studies conducted in the USA, African-American/Black and Hispanic populations experienced higher rates of SARS-CoV-2 infection and COVID-19-related mortality compared with non-Hispanic White populations, and Asian populations appeared to have similar rates of infections, hospitalizations, and deaths as non-Hispanic White populations [50]. The American Heart Association's COVID-19 Cardiovascular Disease Registry study [51] recently reported that Hispanic and Black patients accounted for more than half of patients hospitalized with COVID-19, and the Black and Hispanic patients represented more than half of all in-hospital deaths, indicating that these populations are more likely to be hospitalized with SARS-CoV-2 infection and therefore bear a disproportionate burden of COVID-19 mortality. In addition, Asian patients had a higher probability of experiencing greater COVID-19 cardiorespiratory disease severity than non-Hispanic White patients [51].

The disparities in the susceptibility and mortality of COVID-19 in different races/ethnicities may be caused by the representation of the essential workforce services, poverty, access to healthcare, and insurance, which may increase the potential exposure to SARS-CoV-2 and community transmission and delay the time from symptom onset to hospitalization for individuals other than the non-Hispanic White population [22].

\section{Healthcare Workers (HCWs)}

Frontline HCWs are one of the groups with the highest risk of SARS-CoV-2 infection, as their daily work requires close personal exposure to COVID-19 patients. In addition, the possibility that infected HCWs could potentially contribute to exacerbating the chain of transmission in hospitals and outside health facilities made this group of individuals more distinctive [52]. During the early phase of the COVID19 pandemic, it was suggested that frontline HCWs may account for a high rate of all diagnoses [53,54], which may be due to the shortage of personal protective equipment (PPE) or inadequate disinfection protocols.

The results of a prospective population-based selfreport study [55] using data from a smartphone-based application enrolled more than 2 million consecutive users in the UK and USA and suggested that frontline HCW had an approximately threefold increased risk of reporting a positive COVID-19 test and predicted COVID-19 infection, compared with the general population, and the HCW who worked in an in-patient setting and nursing homes had the greatest risk. The re-use of PPE or inadequate PPE may account for the subsequent increased risk of COVID-19 in frontline HCWs [55]. In contrast, a large retrospective cohort study investigated the proportions of infection, hospitalization, and ICU admission due to COVID-19 in 72,909 individuals and found that there was no significant difference in the odds of having a positive COVID-19 test between HCWs and non-HCWs. Moreover, HCWs had lower odds of subsequent hospitalization. For those who tested positive for SARS-CoV-2, no significant differences were found in ICU admission rates between HCWs and non-HCWs [56]. This is in line with the conclusion from another meta-analysis, which reported that the outcomes of COVID-19 in HCW remained markedly better than those in the general population [57].

As expected, with the ongoing pandemic, implementation of risk-mitigation measures, sufficient availability of PPE, proper quality of PPE, and establishment of mandating protective protocols against COVID-19 infections have led to a decrease in infections among HCWs [58].

\section{Protective Factors for COVID-19 Infection}

\section{Diet and Nutrition}

An appropriate and healthy diet is thought to be a protective factor against COVID-19. Micronutrients (vitamins $\mathrm{C}$ and $\mathrm{D}$, and minerals), proteins, dietary fiber, short-chain fatty acids, and omega-3 polyunsaturated fatty acids may have a positive effect during COVID-19 infection and potentially improve the prognosis of COVID-19 [8].

Vitamin D plays an important immunomodulatory role in the innate and adaptive immune systems. One of its most important functions is the downregulation of proinflammatory cytokines, such as interleukin (IL)-1, IL-6, IL-8, IL-12, and tumor necrosis factor (TNF)- $\alpha$ [23]. A recent study [59] demonstrated that serum levels of 25-OHvitamin D were lower in severe COVID-19 patients than in mild patients and in non-infected controls, suggesting that 
vitamin D insufficiency may favor SARS-CoV-2 infection and COVID-19 progression to critical illness. Moreover, vitamin D level was inversely correlated with the clinical outcomes of COVID-19, independent of inflammatory markers (e.g., IL-6 and C-reactive protein [CRP]), age, or the presence of major comorbidities such as obesity, diabetes, and hypertension. This conclusion is in line with those of previous studies $[60,61]$. Conversely, vitamin D supplementation may reduce the risk of infection and death from infectious disease, and adequate vitamin D levels may help in protecting the respiratory epithelium from pathogenic invasion, thereby decreasing the risk of infection [12]. Vitamin C also has an immunomodulatory effect by reducing the levels of pro-inflammatory cytokines (e.g., TNF- $\alpha$ ) and increasing the levels of anti-inflammatory cytokines (IL-10). A case study reported that a patient with acute respiratory distress syndrome (ARDS) was successfully weaned from mechanical ventilation after 5 days of treatment with high-dose vitamin $\mathrm{C}$, yet antiviral medications were also administered [25]. Dietary insufficiency of vitamins and minerals has been observed in high-risk COVID-19 patients, such as the elderly, which may account for the increased risk of infection [24]. Diets with high percentages of processed food, together with a sedentary lifestyle, may increase the prevalence of hypertension and diabetes, which are risk factors for developing cardiovascular diseases, and in turn increase the risk of COVID-19 infection [62].

In conclusion, avoidance of nutrient deficiencies and practical, effective diet and nutrition may help strengthen the resilience of people to the COVID-19 pandemic. Cohort studies with a large sample size of COVID-19 patients are required to clarify the correlations between diet, nutrition, and COVID-19 hospitalization.

\section{Vaccines}

In this long-lasting pandemic, efficacious COVID-19 vaccination is the most critical strategy to induce a protective immune response and may thus be the only way to prevent the spread of infection and the progression to severe disease and death from this disease [63]. To date, 137 candidate COVID-19 vaccines are in clinical development, and 194 are in preclinical development, using a range of vaccine platforms, including inactivated vaccines, live attenuated vaccines, viral vector-based vaccines, subunit (recombinant protein) vaccines, DNA vaccines, and RNA vaccines [64]. Most COVID-19 vaccine candidates should potently induce robust antibody responses with neutralizing capacity to SARS-CoV-2 (neutralizing antibodies) against the spike protein, which ideally helps to protect vaccinated individuals from viral infection [13].

A study examined the safety, tolerability, and immunogenicity of CoronaVac (inactivated SARS-CoV-2 vaccine) in healthy adults aged 18-59 years and demonstrated that the seroconversion rate of neutralizing antibodies was $97 \%$ $(114 / 117)$ in the $3 \mu \mathrm{g}$ group, and $100 \%$ (118/118) in the $6 \mu \mathrm{g}$ group on day 28 after two doses of vaccine in the phase II trial. Similar results were found in healthy adults aged 60 years and older, with a seroconversion rate of $98 \%$ (96/98) and 99\% (97/98) in the $3 \mu \mathrm{g}$ and $6 \mu \mathrm{g}$ groups, respectively, on day $28[65,66]$. Additionally, a recent preliminary report from Brazil also showed that CoronaVac significantly decreased the number of confirmed symptomatic cases of COVID-19 in HCWs [67].

Preclinical data of BNT162b2 (mRNA vaccine) showed no detectable viral RNA in bronchoalveolar lavage fluid or in nasal swabs in male rhesus macaques after challenge with SARS-CoV-2, which indicates that the vaccine protected the animal model from SARS-CoV-2 infection [68]. Furthermore, a trial in the USA showed that the administration of two doses of BNT162b2 or mRNA-1273 was $88.7 \%$ effective in preventing SARS-CoV-2 infection at least 36 days after the first dose [69]. Another study involving HCW and first responders in the USA showed an effectiveness of $90 \%$ in reducing RT-PCR-confirmed SARS-CoV-2 infection after two doses of mRNA vaccines [70]. Theoretically, the induction of immunological memory by the COVID-19 vaccine might play an important role in the prevention of re-infections. A recent pilot study showed that much higher levels of SAR-CoV-2 S protein-specific antibodies were produced after a single dose of BNT162b2 in individuals with prior COVID-19 in the past 9-12 months, compared to those without prior infection, suggesting that vaccination can boost immune memory and prevent COVID-19 re-infection [71]. As reduction in infections requires regular testing of all subjects to detect subclinical infections, further investigations are required to optimize the vaccine candidates [13].

Currently, a large number of phase III and phase IV clinical trials of various vaccine candidates are still ongoing, and more complete data are expected to reveal the protective effect of vaccines against SARS-CoV-2 infection, especially the performance against COVID-19 variants, and the duration of protection in real-world conditions.

\section{Atopic Conditions}

Atopic status is probably a genetic predisposition to produce a type 2 immune response upon exposure to environmental antigens. The association between atopic conditions, infection, and severity of COVID-19 has been studied by many researchers.

Keswani et al. [14] conducted a large two-site cohort study of 1,043 patients with RT-PCR-confirmed SARSCoV-2 infection, and the results showed that $24.6 \%$ (257/1043) cases had atopy conditions (defined as the presence of allergic rhinitis (AR) and/or eczema and/or food 
allergy). In addition, atopy was associated with significantly lower odds and decreased duration of hospitalization for COVID-19 compared to non-atopic patients. As for the subgroups, AR and eczema patients had lower odds of COVID19 hospitalization, and AR was associated with reduced hospitalization duration and intubation rate. No difference in mortality was identified between patients with and without atopic conditions. A retrospective study in Italy found a much lower occurrence of severe COVID-19 in patients with atopic disease than in non-atopic individuals, and the "protective" effect of atopic status against severe disease was evident in all age subsets [72]. In addition, data from a study in the USA supported the finding that no difference in severity of COVID-19 between those with and without pre-existing atopic diseases and food allergy may reduce the likelihood of hospitalization with COVID-19 [73].

The expression of ACE2 was previously found to decrease in individuals with atopy [27]. In addition, decreased ACE2 levels were correlated with allergic sensitization, high levels of total immunoglobulin E (IgE), and type 2 inflammatory cytokines, such as IL-13 [74]. Thus, decreased ACE2 expression in type 2 inflammation may be one of the underlying mechanisms for the protective role of atopy against COVID-19.

The effect of pre-existing asthma on COVID-19 infection and severity is still under debate, which will be discussed in a later section of this review.

\section{Risk Factors for the Severity and Mortality of COVID-19 Disease Progression in Adults}

\section{Older Age}

Apart from the increased risk of COVID-19 infection, age is also considered to be a factor affecting disease progression and mortality risk among those infected. In previous studies, the proportion of infections that eventually progress to severe and critical disease, or death, increases rapidly with age, especially among those $\geq 50$ years of age $[54,75,76]$. According to the data from 79,394 COVID-19 patients in China, the mortality rate for patients aged $>59$ years was $~ 5.1$ times higher than that of patients aged $30-59$ years after symptom development [77]. In a meta-analysis involving 212 studies and 281,461 individuals from 11 countries/ regions, it was found that among patients with severe COVID-19, the pooled mean age was 60.4 years, and more than half $(61 \%)$ were male [78]. Another meta-analysis also showed that COVID-19 patients aged $>70$ years appear to have a higher risk of severe disease, need for intensive care, and death [16].

As mentioned above, aging is usually associated with a high prevalence of comorbidities and decreased reserve capacity of vital organs, which may lead to increased frailty. In addition, an aged immune system and higher SARSCoV-2 viral load in elderly individuals may put them at risk of a poor outcome and higher risk of mortality when infected with COVID-19 [8].

\section{Male Sex}

Previous studies have shown that men are predisposed to being more severely affected by COVID-19. A meta-analysis of 59 studies comprising 36,470 patients [16] showed that men experienced more severe disease than women (RR: $1.18,95 \% \mathrm{CI}: 1.10$ to 1.27$)$. Moreover, the rate of ICU in COVID-19 patients was higher among men. Furthermore, it was observed that men were at a higher risk of death from COVID-19 than women (RR: $1.50,95 \%$ CI: 1.18 to 1.91 ) [16]. Li et al. conducted a meta-analysis of 281,461 individuals and found among patients with severe COVID-19, $61 \%$ were men. In addition, more males were in the severe group $(60.8 \%, 95 \%$ CI: $57.2-64.2)$ than in the non-severe group $(47.6 \%, 95 \%$ CI: 44.9-50.4) [78].

The increased severity and mortality of COVID-19 in men may imply an underlying biological mechanism. Usually, men tend to be associated with unhealthy lifestyles, such as smoking, and more comorbidities. Although the effect of smoking on the severity of COVID-19 remains unclear, COPD, which can be caused by long-term smoking, has been reported as a risk factor for severe disease or death from COVID-19 [79]. Elevated expression of ACE2 receptor in the airway epithelia [80] and the increased likelihood of exacerbations caused by respiratory virus infection may put COPD patients at a high risk of the progression of COVID-19 [81].

In comparison to estrogen, testosterone may predispose men to COVID-19 infection. Low testosterone levels in aging hypogonadal males may exacerbate the severity of COVID-19 [20]. Apart from anatomical, lifestyle, behavioral, comorbidities, and socioeconomic differences between men and women, the protective role of $\mathrm{X}$ chromosome and hormones in innate and adaptive immunity may also predispose women to be less susceptible to viral infection than men $[16,82,83]$.

\section{Pre-existing Comorbidities}

Many studies have demonstrated that the presence of comorbidities is more common among patients with severe COVID-19, including cardiovascular diseases [84-86], hypertension [85, 87], diabetes [84-86], COPD [85-87], malignancy [86, 87], cerebrovascular diseases [85], and chronic kidney disease [88]. 
A meta-analysis showed that the comorbidities of hypertension, diabetes, and cardiovascular diseases conferred a higher risk of severe COVID-19, ICU admission, and overall fatal outcomes in patients across all age groups [89]. In addition, two studies reported that obesity $(\mathrm{BMI} \geq 30)$ was associated with more severe disease and worse outcomes in COVID-19 patients [90, 91]. The detrimental restrictive ventilatory effects of abdominal fat, prothrombotic conditions within the cardiovascular system, immune dysregulation, chronic inflammation, highly expressed ACE2 in the epicardial adipose tissue, liver steatosis and abnormal liver function, lower vitamin D concentrations, and possible gut barrier leakiness are the potential biological mechanisms that cause the increased severity of COVID-19 in obese populations [8]. The sustained low level of immunity in patients with diabetes and hypertension will lead to reduced resistance to viral infections. Long-term diabetes and hypertension can damage the vascular structure and weaken the heart function, which makes these patients more likely to develop critical disease in COVID-19 [30]. Patients with cardiovascular disease or related risk factors were at a significantly higher risk of poor clinical outcomes following COVID-19 [89]. Patients with a history of cardiovascular disease were more likely to develop severe cases, as COVID-19 can promote acute cardiac injury [92].

COVID-19 is assumed to be able to damage organs including the liver, kidneys, heart, and other organs, and pre-existing comorbidities of these organs further promote the progression of COVID-19 and lead to severe and fatal outcomes [11]. Therefore, it is necessary to give special attention for disease prevention and control in these highrisk populations with pre-existing comorbidities [78].

\section{Laboratory Indices}

The characteristics of severe COVID-19 infection include hyperinflammatory syndrome, cytokine storm, ARDS, and pulmonary, cardiac, and/or renal damage [11]. Meta-analyses of multiple studies have shown significant correlations between several laboratory factors and the severity and mortality of COVID-19. These laboratory parameters included the following: (1) changes in blood cell counts, including increased leukocyte and neutrophil counts, neutrophil-to-lymphocyte ratio, and decreased lymphocyte and eosinophil counts; (2) increase in the level of biochemical parameters: lactate dehydrogenase, CRP, procalcitonin, aspartate amino transferase, alanine aminotransferase, and blood urea nitrogen; and (3) changes in coagulation indicators: decreased platelet counts, increased D-dimer, fibrinogen, change in prothrombin time (PT), and activated partial-thromboplastin time (APTT). These changes may be associated with an aggravated disease course of COVID-19 [8].
Patients with severe COVID-19 are characterized by lymphocytopenia (low CD3 +, CD4 +, and CD8 + T-cell counts), which may be caused by direct viral cytopathic effects, inhibitory effects of cytokines including TNF$\alpha$, IL-6, and IL-10, and immune cell redistribution into the lungs and lymphoid organs $[9,93]$. The decrease in CD4 + and CD8 + T cells may also be attributed to lymphocyte consumption during the infection process $[2,75$, 94, 95]. Many studies have demonstrated that eosinopenia is more prominent in patients with severe COVID-19 than in mild patients. We have also suggested that the degree of eosinopenia may serve as a potential predictive factor for the severity of COVID-19 [96, 97]. Coagulation factors are strongly associated with disease severity or fatality. A high incidence of thromboembolic events has been reported in deceased COVID-19 patients, which may be caused by COVID-19-triggerred coagulation disorders [98-100]. In addition, prolonged PT and APTT are associated with anticoagulants, coagulation factor deficiency, and fibrinolysis. A few studies have shown shortened PT and APTT in severe COVID-19 patients [10], while others have reported prolonged PT and APTT [101]. A recent metaanalysis found no difference in PT and APTT between the severe and non-severe groups upon admission [98]. More clinical trials are needed to investigate the relationship between PT/APTT and COVID-19 severity. In summary, monitoring the above-mentioned changes in laboratory indices will be helpful for clinicians to improve treatment regimens, prevent disease progression, and reduce the risk of death from COVID- 19.

\section{Pro-inflammatory Cytokines}

COVID-19 can trigger a hyperinflammatory condition, which is potentially life-threatening and may lead to fatality in severe cases [102]. "Cytokine storm" usually takes place in patients at advanced stages of COVID-19 and develops a rapid inflammatory signaling cascade [33]. It occurs in response to sustained hyperinflammation and can cause hypercoagulability in the microvasculature, which then leads to tissue injury, disseminated intravascular coagulation, and subsequent multi-organ failure [103].

Severe COVID-19 is characterized by significantly increased levels of pro-inflammatory cytokines, which are produced by a dysregulated immune response [9]. Patients with severe COVID-19 had significantly higher levels of circulating IL-6, IL-8, IL-10, IL-2R, and TNF- $\alpha$ compared to mild-to-moderate cases [32]. As an inhibitor of the inflammatory response, IL-10 can not only prevent $\mathrm{T}$-cell proliferation but also induce $\mathrm{T}$-cell exhaustion in severe patients. Therefore, the elevated level of IL-10 may lead to an impaired ability to clear viral infections 
in severe patients due to the negative regulation of T-cell survival or proliferation [104]. Type I interferons (IFN-I) are vital for immunity against viral infections. However, coronavirus infection is considered to result in hyperinflammation induced by IFN-I [105]. Activation of IFN-I signaling pathways leads to a significant influx of neutrophils, inflammatory monocytes, macrophages, dendritic cells, and natural killer cells into the lungs. These infiltrating cells are the major source of inflammatory cytokines that trigger a cytokine storm [106]. Severe and critically ill COVID-19 patients may have impaired IFN-I activity. In older adults with high viral exposure, delayed IFN-I responses can lead to viral persistence, inflammation, and severe disease [8].

\section{Complications}

For complications developed during the COVID-19 infection, organ failure [34], immunological dysfunction [34], acute liver injury [35], hypoproteinemia [35], ARDS [36], severe pneumonia [100], uncontrolled inflammation response [100], and hypercoagulable state [100] were found to have a significant impact on disease severity. In addition, acute kidney injury, shock, cardiac death, thrombocytopenia, hypoxemia, and dyspnea have also been identified as risk factors for COVID-19 mortality [11, 78]. Thus, early identification of complications and prompt intervention should be able to decrease COVID-19 mortality.

\section{Protective Factors for the Severity and Mortality of COVID-19 Disease Progression}

\section{Vaccine}

An efficacious COVID-19 vaccine can reduce the severity of the disease resulting from SARS-CoV-2 infection. The protective effect of the vaccine should not depend solely on the induction of antibodies but also on the establishment of immune memory, including the induction of T-cell activation.

Taking CoronaVac as an example, evidence has shown that after a SARS-CoV-2 challenge, CoronaVac was able to protect macaques from severe interstitial pneumonia, and no antibody-dependent enhancement of infection was observed [107]. In addition, the initial results investigating CoronaVac released by researchers in Brazil reported that the vaccine was $50.4 \%$ effective at preventing both severe and mild diseases in HCWs. Although the percentage is relatively lower than earlier trials conducted in Turkey and Indonesia (91.2\% and $65.3 \%$ effective, respectively), no vaccinated $\mathrm{HCW}$ in this Brazil trial required hospitalization due to COVID-19 [108].
In a phase III trial of $100 \mu \mathrm{g}$ mRNA-1273 (mRNA COVID-19 vaccine) which included 30,420 adults with no known history of SARS-CoV-2 infection [109], 30 severe cases were reported in the placebo group, and none was reported in the mRNA-1273 vaccinated group after two doses of intramuscular administration, indicating $100 \%$ efficacy in preventing severe COVID-19 of mRNA-1273. In addition, a phase II/III international trial of $30 \mu \mathrm{g}$ BNT162b2 (mRNA vaccine) [110] reported 10 cases of severe COVID19 in total after the first dose of vaccine administration, of which only one case in the vaccine group and the remaining nine in the placebo group.

A recent case series from the China Centers for Disease Control and Prevention reported three cases of COVID19 delta variant infection with and without vaccination in Chengdu City [111]. Two of the cases were vaccinated with two doses, whereas one case was not vaccinated. The IgG/ IgM/total antibody tests were positive for the two vaccinated cases on the 4th and 1st day, but negative for the unvaccinated case even on the 7th day, which suggested that the time from diagnosis to antibody positivity was shorter in vaccinated cases than in unvaccinated cases. In addition, the length of hospitalization was shorter in vaccinated patients than in unvaccinated patients. This information suggests that efficacious COVID-19 vaccines can rapidly alert the immune system to produce protective antibodies against the virus and reduce the duration of hospitalization due to infection.

Intriguingly, although the majority of the route of administration of the current COVID-19 vaccine is via intramuscular injection, other routes of administration are also under development, such as intranasal administration. Compared with the humoral and cellular responses induced by the injectable vaccine, the inhaled vaccine should be able to efficiently induce mucosal antibody response, thereby potentially providing sterilizing immunity in the upper respiratory tract [112]. The beneficial effects of various vaccines on COVID-19 severity and clinical outcomes require further investigation in the duration of protection and establishment of immune memory in real-world studies.

\section{Uncertain Factors}

\section{Therapeutic Treatments}

Currently, no evidence-based strategy has been shown to be effective for the treatment of COVID-19. Most drugs currently used in clinical practice, including hydroxychloroquine/chloroquine (HCQ/CQ), lopinavir/ritonavir (LPV/r), arbidol, remdesivir, traditional Chinese medicine, and convalescent plasma (CP), are repurposed drugs initially designed for the treatment of other diseases and are aimed at improving the clinical outcomes of infected patients [113]. 
According to a meta-analysis that included data from 42 studies, HCQ treatment was not found to be associated with a lower risk of death compared to control groups, but it may be effective in terms of time for body temperature normalization and clinical symptom alleviation. It was assumed that HCQ could bring few benefits with respect to the incidence of severe COVID-19 and clearance of viral RNA, but was more likely to have adverse reactions, especially QT prolongation [114].

Several studies have concluded that no beneficial effect of HCQ or chloroquine was observed in patients hospitalized with COVID-19 on the risk of death, and probably no effect on progression to mechanical ventilation; in addition, adverse events are largely increased compared to placebo $[115,116]$. Data from several trials showed that LPV/r did not decrease the time to clinical improvement compared with the standard care group, suggesting a limited role of LPV/r in the treatment of COVID-19. Also, LPV/r and arbidol monotherapy did not significantly reduce the viral clearance time $[117,118]$. In contrast, another study reported that patients receiving combined therapy with LPV/r and arbidol recovered successfully from COVID-19 [119].

A double-blind randomized trial [120] showed that intravenous remdesivir decreased the time to recovery in adults when compared to the placebo group, which suggested that remdesivir may reduce the mortality rate and adverse reactions in severe patients, although some controversial results still exist [121, 122].

Several clinical trials have been conducted to assess the efficacy and safety of tocilizumab, an IL-6 receptor antagonist, in COVID-19. A Cochrane Database systemic review based on these trials concluded that tocilizumab [123] was able to reduce all-cause mortality at day 28 compared to standard care alone or placebo and may result in fewer severe adverse events (SAEs). However, the clinical improvement (defined as hospital discharge or improvement measured by trialist-defined scales) was negligible or absent in those treated with tocilizumab at day 28.

Nevertheless, a recent systematic review with metaanalyses and trial sequential analyses including trials until November 2, 2020, revealed that no evidence-based treatment currently exists for COVID-19, as very low certainty of evidence indicates that corticosteroids, remdesivir, intravenous immunoglobulin (IVIG), tocilizumab, and bromhexine might reduce the risk of death, adverse events, and mechanical ventilation [124]. Similarly, a recent international multicenter trial involving patients from 30 countries investigated the effects of remdesivir, HCQ, lopinavir/ritonavir, and IFN$\beta 1$ a on COVID-19 treatment, and the results showed little or no effect of these drugs on the mortality of hospitalized COVID-19 patients [121]. However, the conclusive findings from this trial remain unclear.
Interestingly, one study using survival analysis confirmed that dexzopiclone, a commonly prescribed hypnotic drug for insomnia, was significantly associated with favorable outcomes in COVID-19 patients [125]. Favorable clinical outcomes were more prevalent among patients on hypnotics compared to non-hypnotics, in non-severe $(94.7 \%$ vs. $88.5 \%$ ), severe ( $95 \%$ vs. $74.6 \%$ ), and critically ill (66.7\% vs. $13.0 \%$ ) patients, indicating that hypnotics may be an effective ancillary treatment for COVID-19. With the administration of hypnotics, COVID-19 patients may be able to have better sleep quality and reduce stress during hospitalization, thereby enhancing the immune response and improving the survival and recovery of these patients.

Further wide and large-scale clinical trials are required to obtain more reliable findings regarding different therapies.

\section{Asthma}

Conflicting results have been reported regarding the association between asthma and COVID-19 susceptibility and severity. Similar to other infectious diseases affecting the lungs, asthma was once regarded as a potential risk factor for severe COVID-19 in several studies, as it is susceptible to viral-induced exacerbations [126-128]. An early case series of adults hospitalized with COVID-19 in 14 USA states reported that asthma was one of the most prevalent comorbid conditions (prevalence $=17 \%$ ) [129], and a higher asthma prevalence was observed in patients with COVID-19 in the first 393 consecutive patients with COVID-19 in New York City (prevalence $=12.5 \%$ ), suggesting that asthma is more common in COVID-19 patients [91]. However, despite a few studies describing a poor prognosis in COVID-19 patients who were asthmatic, asthma has not been consistently identified as a significant comorbidity related to COVID-19. For example, the initially conducted case series from China did not specify asthma as a risk factor for severe COVID-19 $[130,131]$. Instead, asthmatic patients were found to be at a reduced risk of COVID-19 hospitalization and severity in several large COVID-19 cohort studies [132, 133]. Furthermore, a recent meta-analysis including 161,271 COVID-19 patients [134] showed that asthma as a premorbid condition was present in only $1.6 \%$ of all patients, which is much lower than the prevalence of asthma in the general population worldwide [135]. These studies suggest that asthma is more likely to be a protective factor against COVID-19. These inconsistent findings may be related to the heterogeneity of asthma endotypes (allergic asthma vs. non-allergic asthma). A population-based prospective cohort study comprising 492,768 participants from the UK Biobank [131] showed a significantly higher risk of severe COVID-19 in non-allergic, but not allergic asthma patients. Another study also reported a prolonged 
intubation time in COVID-19 patients with non-allergic asthma, but not in those with allergic asthma [14]. Abnormal immune response occurring in the context of an allergic condition and abnormal respiratory function has been suggested as an explanation for this association [136]. The conclusion is in line with previous findings, which suggest allergic asthma may not be a risk factor for COVID-19, particularly when it is well-controlled [14, 137]. These findings suggest a potential "protective" role of allergic asthma, whereas non-allergic asthma predisposes patients to COVID-19.

As for the underlying mechanisms, a study has demonstrated a higher expression of TMPRSS 2 in bronchial airway epithelium biopsies from asthmatic patients. This result indicates that once infected, a more efficient facilitation of SARS-CoV-2 entry and enhanced internalization after receptor binding in the airway epithelium occurs in asthmatic patients, which may increase the susceptibility to faster progression of COVID-19 to more severe forms in asthmatic patients [138]. Sajuthi et al. also demonstrated that TMPRSS 2 expression in airway epithelial cells was highly upregulated by type 2 inflammation mainly via the effect of IL-13 [139].

However, a decreased expression of ACE2 in asthmatics, compared to healthy controls, has also been observed [140]. The limited expression of ACE2 on the target cells in asthmatic patients with COVID-19 may be caused by deficient IFN-I responses in these patients, as ACE2 is an interferon-stimulated gene in human airway epithelial cells [141]. Meanwhile, asthma with a higher allergic sensitization was found to be associated with a lower expression level of ACE2 in the nasal and bronchial epithelium, indicating a decreased risk of COVID-19 susceptibility and severity in allergic asthma patients [27]. T helper 2 (Th2)-skewed immunity may be protective against severe COVID-19 disease due to the cross-regulation between allergic and interferon-mediated immune responses [142]. Additionally, the beneficial impact of the therapeutic use of inhaled corticosteroids (ICSs) in asthmatic subjects may also contribute to the reduction in the risk of hospitalization due to COVID-19 [143, 144]. In fact, a reduced expression of ACE2 and TMPRSS2 was observed in sputum samples from asthmatic patients treated with ICSs $[145,146]$. In addition, omalizumab, a monoclonal antibody for the treatment of asthma via blocking free IgE, can downregulate high-affinity IgE receptors on plasmacytoid dendritic cells (pDCs), which is essential for antiviral immune responses and reducing disease exacerbation $[147,148]$.

More comprehensive and in-depth immunological analyses are needed to clarify the interactions of asthma with COVID-19 and the underlying mechanisms, which may be advantageous for future prevention and treatment strategies.

\section{Risk Factors for SARS-CoV-2 Infection and Severity in Children}

Compared to adult patients, currently available studies suggest that the pediatric population is much less commonly and less severely affected by SARS-CoV-2, with approximately $5 \%$ cases and extremely low $(0-0.69 \%)$ fatality rate $[4,149]$. This may result from a healthier airway tract of the children, as they are less exposed to cigarette smoke and environmental pollution than adults and therefore stronger respiratory epithelial cells to defend against SARS-CoV-2 [48]. In addition, a lower expression level of the ACE2 receptor in the nasal epithelium in children may also contribute to the decreased susceptibility to infection and severity of disease $[150,151]$. Children are protected against SARS-CoV-2 probably because ACE2 is less mature at younger ages [149].

Currently, there are only limited studies concerning severe COVID-19 in children. Evidence has shown that a few risk factors for infection and severity in adult COVID-19 patients may also play a similar role in pediatric COVID19 , including age and underlying chronic comorbidities [4, 152-154].

\section{Age}

Age has been reported as an important factor associated with infection and severity in pediatric COVID-19 patients. In an early series of 2,135 COVID-19 children from China, children younger than 1 year accounted for $10.6 \%$ of the severe and critical cases, the highest percentage among all pediatric age groups [4]. These results suggest that young children, particularly infants, may be vulnerable to SARSCoV-2 infection. Similarly, in a large pediatric cohort study with over 36,000 pediatric cases of SARS-CoV-2 in Colorado, USA, extremes of age (either $<3$ months or $>20$ years old) were found to be predictive of severe COVID-19 [5]. Another retrospective cohort study including 177 pediatric and young adult COVID-19 patients from Washington, USA, also noted a bimodal distribution of patients: children $<1$ year of age and young adults $>15$ years of age represented the highest proportion of patients within the hospitalized and critically ill cohorts [155]. The results of other studies also supported a U-shaped gradient of severity in children diagnosed with COVID-19: young infants and older adolescents were at higher risk of severe disease [154, 156, 157].

However, in contrast with the results from the reports mentioned above, which led to specific concerns regarding the young infant group, a French national prospective surveillance of children hospitalized with SARS-CoV-2 infection suggested the lowest rate of severe forms of COVID-19 in very young children ( $<90$ days), although they accounted for $37 \%$ of all hospitalized children [158]. This discrepancy 
may be due to the various definitions of severe forms of disease in different studies.

\section{Pre-existing Comorbidities}

As mentioned above, specific comorbidities are identified as risk factors not only for infection and admission to the ICU but also for mortality in adult COVID-19 patients. However, few studies have reported severe cases in pediatric patients.

Although children are less susceptible to COVID-19, the pre-existing comorbid conditions can predispose to severe disease within the population. A meta-analysis conducted by Tsankov et al. summarized the relationship between COVID-19 infection and pediatric comorbidities in 42 studies containing 275,661 children [6]. The results showed that children with comorbidities had a relative risk ratio of 1.79 for severe COVID-19 infection and 2.81 for COVID19 -associated mortality, respectively.

A large cohort study in the UK included 26,322 young COVID-19 patients aged $<18$ years and found that comorbidities associated with hospital admission included type 1 diabetes, congenital heart disease, cerebral palsy, epilepsy, and sickle cell disease [7]. In addition, immunocompromised and gastrointestinal conditions have also been reported as predictors of admission [5].

Of note, as an increasingly common condition in children, obesity has been described as one of the most significant factors associated with mechanical ventilation in children aged 2 years and older with COVID-19 [31]. Results from other studies also support the notion that obesity and type 2 diabetes are predictive of severe pediatric COVID-19 [5, 159]. Furthermore, other specific comorbidities were also found to be associated with more severe diseases in those hospitalized with COVID-19, such as cardiovascular disease, malignancies, and immunosuppression [159-161]. Data from a European study demonstrated that the most common comorbidities associated with admission to pediatric intensive care were chronic lung disease, congenital heart disease, neurological disease, or malignancy [154].

\section{Asthma}

Asthma was determined to be a common underlying medical condition in pediatric COVID-19 patients in some studies. Similar to the adult population, it is also currently unclear whether asthma could affect the infection and severity of COVID-19 in children.

Few studies have demonstrated that asthma may be a potential risk factor for COVID-19 in children. Kelly et al. found that asthma was significantly associated with admission $(\mathrm{aOR}=2.2)$ and the need for respiratory support among 454 patients with SARS-CoV-2 infection [5]. In another cross-sectional study evaluating the impact of comorbidities on pediatric COVID-19 patients, it was reported that children with asthma were 4.1 times more likely to have moderatesevere COVID-19 [157].

On the contrary, there is evidence showing that pediatric asthma has no impact or even plays a protective role against the development of severe SARS-COV-2 infection. Cohort studies from the UK and Mexico found no significant association between asthma and hospital admission in pediatric patients [7, 162]. In addition, in a study involving more than 19,000 COVID-19 patients who presented to the emergency department (ED) across 45 US children's hospitals, asthma was found to be associated with an increased risk of hospitalization, compared to pediatric COVID-19 patients discharged from the ED. However, asthma did not increase the risk of more severe diseases among hospitalized patients [159]. Similarly, in a Washington cohort study, although the most frequent underlying diagnosis in the overall group was asthma $(35 / 177 ; 20 \%)$, the proportion of children and young adults with asthma in the hospitalized (16\%) or critically ill cohort (22\%) was not significantly higher than that in the non-hospitalized cohort (21\%) or non-critically ill cohort (14\%) [155]. The results from a cohort study by Floyd et al. showed an inverse association between pediatric asthma and COVID-19 hospitalization [163].

Several mechanisms have been proposed for the potential protective effect of asthma against hospitalization and severity of COVID-19, including lower IFN- $\alpha$ production, the protective role of eosinophils in the airway, the daily protective behaviors of these patients, and the antiviral and immunomodulatory effects of asthma control medication (such as inhaled steroids) [26, 28]. Furthermore, type 2 inflammation-induced under-expression of ACE2 receptor and increased TMPRSS2 expression in nasal and bronchial epithelial cells in children with type 2 rhinitis and asthma may also contribute to the protective role of asthma and atopy against SARS-CoV-2 [27, 74]. More in-depth research into the relationship between childhood asthma and COVID19 is required.

\section{Laboratory Indices}

Normal or increased leukocyte count, decreased lymphocyte counts, significantly elevated inflammatory markers (CRP, procalcitonin, lactate dehydrogenase, and D-dimer), elevated platelet count, and other laboratory parameters were noted in children who developed severe COVID-19, compared to mild and moderate forms of the disease [157, 158, 164-166]. This is similar to findings in adults. Furthermore, a significant decrease in T-cell subsets and low levels of complement $\mathrm{C} 3$ and $\mathrm{C} 4$ in the acute stage of the disease were also found to be associated with the severity of COVID-19 in children [167]. These laboratory indices may help determine the severity of the disease in pediatric patients. 


\section{Conclusion}

This comprehensive review summarizes the potential risk and protective factors for COVID-19 infection, severity, and mortality in both adults and children. In adults, demographic factors such as older age, male sex, ethnicity, and pre-existing comorbidities are thought to be risk factors for disease development and severity. Laboratory indices and complications developed during hospitalization may be predictive factors for the severity and mortality of COVID-19. A healthy diet, sufficient supply of nutrition, vaccination, and atopy may be protective factors against infection and progression of the disease. The roles of several factors, such as therapeutic treatments and asthma, are currently uncertain, with conflicting results. In children, infection is generally less prevalent and severe than in adults. Younger children and pre-existing comorbidities such as obesity have a predisposition to critical illness following infection with COVID-19; thus, additional care of these populations may be required.

Further studies are warranted to identify other potential risk and protective factors for COVID-19 and clarify the underlying mechanisms in order to improve the management of patients with COVID-19 and to help in the development of new forms of treatment. Standardized studies with a large sample size are urgently needed to inform stratified approaches to rapidly protect the population groups at risk.

Currently, the variant strains of SARS-COV-2 are imported into many countries and exert a great threat to the prevention and control of COVID-19. Further studies examining the epidemiology and impact of these variants and the effects of vaccination are urgently needed.

Author Contribution Y.G. contributed to the conception and design of this study. J.Z. performed the literature search, drafted, and edited the manuscript. X.D. helped with the data analysis. Y.G. and G.L. critically revised the manuscript and approved the final publication.

\section{Declarations}

Consent for Publication All authors provided consent for the submission of the manuscript.

Conflict of Interest The authors declare no competing interests.

\section{References}

1. World Health Organization (WHO) (2021) Coronavirus disease (COVID-19) weekly epidemiological update and weekly operational update. https://www.who.int/emergencies/diseases/novelcoronavirus-2019/situation-reports. Accessed 27th December 2021

2. Li G, Fan Y, Lai Y et al (2020) Coronavirus infections and immune responses. J Med Virol 92:424-432. https://doi.org/10. 1002/jmv.25685
3. Fauci AS, Lane HC, Redfield RR (2020) Covid-19-navigating the uncharted. N Engl J Med 382:1268-1269. https://doi.org/10. 1056/NEJMe2002387

4. Dong Y, Mo X, Hu Y et al (2020) Epidemiology of COVID-19 among children in China. Pediatrics 145:e20200702

5. Graff K, Smith C, Silveira L et al (2021) Risk factors for severe COVID-19 in children. Pediatr Infect Dis J 40:e137-e145

6. Tsankov BK, Allaire JM, Irvine MA et al (2021) Severe COVID-19 infection and pediatric comorbidities: a systematic review and metaanalysis. Int J Infect Dis 103:246-256

7. Saatci D, Ranger TA, Garriga C et al (2021) Association between race and COVID-19 outcomes among 2.6 million children in England. JAMA Pediatr 175:928-938

8. Gao YD, Ding M, Dong X et al (2021) Risk factors for severe and critically ill COVID-19 patients: a review. Allergy 76:428-455. https://doi.org/10.1111/all.14657

9. Mulchandani R, Lyngdoh T, Kakkar AK (2021) Deciphering the COVID-19 cytokine storm: systematic review and meta-analysis. Eur J Clin Invest 51:e13429. https://doi.org/10.1111/eci.13429

10. Gao Y, Li T, Han M et al (2020) Diagnostic utility of clinical laboratory data determinations for patients with the severe COVID-19. J Med Virol 92:791-796. https://doi.org/10.1002/ jmv. 25770

11. Wolff D, Nee S, Hickey NS, Marschollek M (2021) Risk factors for Covid-19 severity and fatality: a structured literature review. Infection 49:15-28. https://doi.org/10.1007/s15010-020-01509-1

12. Shakoor H, Feehan J, Al Dhaheri AS et al (2021) Immune-boosting role of vitamins D, C, E, zinc, selenium and omega-3 fatty acids: could they help against COVID-19? Maturitas 143:1-9. https://doi. org/10.1016/j.maturitas.2020.08.003

13. Chakraborty S, Mallajosyula V, Tato CM, Tan GS, Wang TT (2021) SARS-CoV-2 vaccines in advanced clinical trials: where do we stand? Adv Drug Deliv Rev 172:314-338. https://doi.org/ 10.1016/j.addr.2021.01.014

14. Keswani A, Dhana K, Rosenthal JA, Moore D, Mahdavinia M (2020) Atopy is predictive of a decreased need for hospitalization for coronavirus disease 2019. Ann Allergy Asthma Immunol 125:479-481. https://doi.org/10.1016/j.anai.2020.07.012

15. Flook M, Jackson C, Vasileiou E et al (2021) Informing the public health response to COVID-19: a systematic review of risk factors for disease, severity, and mortality. BMC Infect Dis 21:342. https://doi.org/10.1186/s12879-021-05992-1

16. Pijls BG, Jolani S, Atherley A et al (2021) Demographic risk factors for COVID-19 infection, severity, ICU admission and death: a meta-analysis of 59 studies. BMJ, (Open) 11:e044640. https://doi.org/10.1136/bmjopen-2020-044640

17. Davies NG, Klepac P, Liu Y et al (2020) Age-dependent effects in the transmission and control of COVID-19 epidemics. Nat Med 26:1205-1211. https://doi.org/10.1038/s41591-020-0962-9

18. Ayoub HH, Chemaitelly H, Mumtaz GR et al (2020) Characterizing key attributes of COVID-19 transmission dynamics in China's original outbreak: model-based estimations. Glob Epidemiol 2:100042. https://doi.org/10.1016/j.gloepi.2020.100042

19. Shaw AC, Joshi S, Greenwood H, Panda A, Lord JM (2010) Aging of the innate immune system. Curr Opin Immunol 22:507-513. https://doi.org/10.1016/j.coi.2010.05.003

20. Papadopoulos V, Li L, Samplaski M (2021) Why does COVID19 kill more elderly men than women? Is there a role for testosterone? Andrology 9:65-72. https://doi.org/10.1111/andr.12868

21. Lisco G, Tullio AD, Stragapede A et al (2021) COVID-19 and the endocrine system: a comprehensive review on the theme. J Clin Med 10:2920. https://doi.org/10.3390/jcm10132920

22. Abedi V, Olulana O, Avula V et al (2021) Racial, economic, and health inequality and COVID-19 infection in the United States. J Racial Ethn Health Disparities 8:732-742. https://doi.org/10. 1007/s40615-020-00833-4 
23. Bouillon R, Marcocci C, Carmeliet G et al (2019) Skeletal and extraskeletal actions of vitamin D: current evidence and outstanding questions. Endocr Rev 40:1109-1151. https://doi.org/10.1210/er.2018-00126

24. Grant WB, Lahore H, McDonnell SL et al (2020) Evidence that vitamin D supplementation could reduce risk of influenza and COVID-19 infections and deaths. Nutrients 12.https://doi.org/ 10.3390/nu12040988

25. Khan HM, Parikh N, Megala SM, Predeteanu GS (2020) Unusual early recovery of a critical COVID-19 patient after administration of intravenous vitamin C. Am J Case Rep 21:e925521. https://doi.org/10.12659/AJCR.925521

26. Boechat JL, Wandalsen GF, Kuschnir FC, Delgado L (2021) COVID-19 and pediatric asthma: clinical and management challenges. Int J Environ Res Public Health 18. https://doi.org/10. 3390/ijerph18031093

27. Jackson DJ, Busse WW, Bacharier LB et al (2020) Association of respiratory allergy, asthma, and expression of the SARS-CoV-2 receptor ACE2. J Allergy Clin Immunol 146:203-206.e3

28. Taquechel K, Diwadkar AR, Sayed S et al (2020) Pediatric asthma health care utilization, viral testing, and air pollution changes during the COVID-19 pandemic. J Allergy Clin Immunol Pract 8:3378-3387.e11. https://doi.org/10.1016/j.jaip.2020. 07.057

29. Pradhan A, Olsson PE (2020) Sex differences in severity and mortality from COVID-19: are males more vulnerable? Biol Sex Differ 11:53. https://doi.org/10.1186/s13293-020-00330-7

30. Zheng Z, Peng F, Xu B et al (2020) Risk factors of critical \& mortal COVID-19 cases: a systematic literature review and metaanalysis. J Infect 81:e16-e25. https://doi.org/10.1016/j.jinf.2020. 04.021

31. Zachariah P, Johnson CL, Halabi KC et al (2020) Epidemiology, clinical features, and disease severity in patients with coronavirus disease 2019 (COVID-19) in a Children's Hospital in New York City. New York JAMA Pediatr 174:e202430. https://doi.org/10. 1001/jamapediatrics.2020.2430

32. Cummings MJ, Baldwin MR, Abrams D et al (2020) Epidemiology, clinical course, and outcomes of critically ill adults with COVID-19 in New York City: a prospective cohort study. Lancet 395:17631770. https://doi.org/10.1016/S0140-6736(20)31189-2

33. Terpos E, Ntanasis-Stathopoulos I, Elalamy I et al (2020) Hematological findings and complications of COVID-19. Am J Hematol 95:834-847. https://doi.org/10.1002/ajh.25829

34. Cao M, Zhang D, Wang Y et al (2020) Clinical features of patients infected with the 2019 novel coronavirus (COVID-19) in Shanghai, China. medRxiv 20030395. https://doi.org/10.1101/ 2020.03.04.20030395

35. Fu L, Fei J, Xu S et al (2020) Acute liver injury and its association with death risk of patients with COVID-19: a hospital-based prospective case-cohort study medRxiv 20050997. https://doi. org/10.1101/2020.04.02.20050997

36. Chen Y, Wang Y, Fleming J et al (2020) Active or latent tuberculosis increases susceptibility to COVID-19 and disease severity medRxiv 20033795. https://doi.org/10.1101/2020.03.10. 20033795

37. Li LQ, Huang T, Wang YQ et al (2020) COVID-19 patients' clinical characteristics, discharge rate, and fatality rate of metaanalysis. J Med Virol 92:577-583. https://doi.org/10.1002/jmv. 25757

38. Guan WJ, Ni ZY, Hu Y et al (2020) Clinical characteristics of coronavirus disease 2019 in China. N Engl J Med 382:17081720. https://doi.org/10.1056/NEJMoa2002032

39. Liu R, Han H, Liu F et al (2020) Positive rate of RT-PCR detection of SARS-CoV-2 infection in 4880 cases from one hospital in Wuhan, China, from Jan to Feb 2020. Clin Chim Acta 505:172175. https://doi.org/10.1016/j.cca.2020.03.009
40. Singh MK, Mobeen A, Chandra A, Joshi S, Ramachandran S (2021) A meta-analysis of comorbidities in COVID-19: which diseases increase the susceptibility of SARS-CoV-2 infection? Comput Biol Med 130:104219. https://doi.org/10.1016/j. compbiomed.2021.104219

41. Guan WJ, Liang WH, Zhao Y et al (2020) Comorbidity and its impact on 1590 patients with COVID-19 in China: a nationwide analysis. Eur Respir J 55. https://doi.org/10.1183/13993003. 00547-2020

42. Chen N, Zhou M, Dong X et al (2020) Epidemiological and clinical characteristics of 99 cases of 2019 novel coronavirus pneumonia in Wuhan, China: a descriptive study. Lancet 395:507-513. https://doi.org/10.1016/S0140-6736(20)30211-7

43. Böhm M, Frey N, Giannitsis E, Sliwa K, Zeiher AM (2020) Coronavirus disease 2019 (COVID-19) and its implications for cardiovascular care: expert document from the German Cardiac Society and the World Heart Federation. Clin Res Cardiol 109:1446-1459. https://doi.org/10.1007/s00392-020-01656-3

44. Zeng JH, Liu YX, Yuan J et al (2020) First case of COVID19 complicated with fulminant myocarditis: a case report and insights. Infection 48:773-777. https://doi.org/10.1007/ s15010-020-01424-5

45. Varga Z, Flammer AJ, Steiger P et al (2020) Endothelial cell infection and endotheliitis in COVID-19. Lancet 395:1417-1418. https://doi.org/10.1016/S0140-6736(20)30937-5

46. Russell B, Moss CL, Palmer K et al (2021) COVID-19 risk factors for cancer patients: a first report with comparator data from COVID-19 negative cancer patients. Cancers (Basel) 13. https:// doi.org/10.3390/cancers13102479

47. Kam KQ, Yung CF, Cui L (2020) A well infant with coronavirus disease 2019 (COVID-19) with high viral load. Clin Infect Dis 71:847-849. https://doi.org/10.1093/cid/ciaa201

48. Tsabouri S, Makis A, Kosmeri C, Siomou E (2021) Risk factors for severity in children with coronavirus disease 2019: a comprehensive literature review. Pediatr Clin North Am 68:321-338. https://doi.org/10.1016/j.pcl.2020.07.014

49. Huang A, Bange E, Han N et al (2021) CD8 T cells compensate for impaired humoral immunity in COVID-19 patients with hematologic cancer. Res Sq. https://doi.org/10.21203/rs.3.rs$162289 / \mathrm{v} 1$

50. Mackey K, Ayers CK, Kondo KK et al (2021) Racial and ethnic disparities in COVID-19-related infections, hospitalizations, and deaths: a systematic review. Ann Intern Med 174:362-373. https://doi.org/10.7326/M20-6306

51. Rodriguez F, Solomon N, de Lemos JA et al (2021) Racial and ethnic differences in presentation and outcomes for patients hospitalized with COVID-19: findings from the American Heart Association's COVID-19 Cardiovascular Disease Registry. Circulation 143:2332-2342. https://doi.org/10.1161/CIRCULATIONAHA. 120.052278

52. Black JRM, Bailey C, Przewrocka J, Dijkstra KK, Swanton C (2020) COVID-19: the case for health-care worker screening to prevent hospital transmission. Lancet 395:1418-1420. https:// doi.org/10.1016/S0140-6736(20)30917-X

53. CDC COVID-19 Response Team (2020) Characteristics of health care personnel with COVID-19-United States, 12 Feb-9 Apr 2020. MMWR Morb Mortal Wkly Rep 69:477-481. https://doi. org/10.15585/mmwr.mm6915e6

54. Wu Z, McGoogan JM (2020) Characteristics of and important lessons from the coronavirus disease 2019 (COVID-19) outbreak in China: summary of a report of 72314 cases from the Chinese Center for Disease Control and Prevention. JAMA 323:12391242. https://doi.org/10.1001/jama.2020.2648

55. Nguyen LH, Drew DA, Graham MS et al (2020) Risk of COVID-19 among front-line health-care workers and the general 
community: a prospective cohort study. Lancet Public Health 5:e475-e483. https://doi.org/10.1016/S2468-2667(20)30164-X

56. Misra-Hebert AD, Jehi L, Ji X et al (2020) Impact of the COVID19 pandemic on healthcare workers' risk of infection and outcomes in a large, integrated health system. J Gen Intern Med 35:3293-3301. https://doi.org/10.1007/s11606-020-06171-9

57. Gholami M, Fawad I, Shadan S et al (2021) COVID-19 and healthcare workers: a systematic review and meta-analysis. Int J Infect Dis 104:335-346. https://doi.org/10.1016/j.ijid.2021.01. 013

58. Galanis P, Vraka I, Fragkou D, Bilali A, Kaitelidou D (2021) Seroprevalence of SARS-CoV-2 antibodies and associated factors in healthcare workers: a systematic review and meta-analysis. J Hosp Infect 108:120-134

59. Campi I, Gennari L, Merlotti D et al (2021) Vitamin D and COVID-19 severity and related mortality: a prospective study in Italy. BMC Infect Dis 21:566. https://doi.org/10.1186/ s12879-021-06281-7

60. Panagiotou G, Tee SA, Ihsan Y et al (2020) Low serum 25-hydroxyvitamin D (25[OH]D) levels in patients hospitalized with COVID-19 are associated with greater disease severity. Clin Endocrinol (Oxf) 93:508-511. https://doi.org/10.1111/cen.14276

61. Hernández JL, Nan D, Fernandez-Ayala M et al (2021) Vitamin D status in hospitalized patients with SARS-CoV-2 infection. $\mathrm{J}$ Clin Endocrinol Metab 106:e1343-e1353:e1343-1343. https:// doi.org/10.1210/clinem/dgaa733

62. Hosseini Z, Whiting SJ, Vatanparast H (2019) Type 2 diabetes prevalence among Canadian adults - dietary habits and sociodemographic risk factors. Appl Physiol Nutr Metab 44:1099-1104. https://doi.org/10.1139/apnm-2018-0567

63. Hodgson SH, Mansatta K, Mallett G, Harris V, Emary KRW, Pollard AJ (2021) What defines an efficacious COVID-19 vaccine? A review of the challenges assessing the clinical efficacy of vaccines against SARS-CoV-2. Lancet Infect Dis 21:e26-e35. https://doi.org/10.1016/S1473-3099(20)30773-8

64. World Health Organization (WHO) (2021) COVID-19 vaccine tracker and landscape. https://www.who.int/publications/m/ item/draft-landscape-of-covid-19-candidate-vaccines. Accessed $27^{\text {th }}$ Dec 2021

65. Zhang Y, Zeng G, Pan H et al (2021) Safety, tolerability, and immunogenicity of an inactivated SARS-CoV-2 vaccine in healthy adults aged $18-59$ years: a randomised, double-blind, placebo-controlled, phase 1/2 clinical trial. Lancet Infect Dis 21:181-192. https://doi.org/10.1016/S1473-3099(20)30843-4

66. Wu Z, Hu Y, Xu M et al (2021) Safety, tolerability, and immunogenicity of an inactivated SARS-CoV-2 vaccine (CoronaVac) in healthy adults aged 60 years and older: a randomised, double-blind, placebo-controlled, phase $1 / 2$ clinical trial. Lancet Infect Dis 21:803-812. https://doi.org/10.1016/S1473-3099(20) 30987-7

67. De Faria E, Guedes AR, Oliveira MS et al (2021) Performance of vaccination with CoronaVac in a cohort of healthcare workers (HCW)—preliminary report medRxiv 21255308. https://doi.org/ 10.1101/2021.04.12.21255308

68. Vogel AB, Kanevsky I, Che Y et al (2020) A prefusion SARSCoV-2 spike RNA vaccine is highly immunogenic and prevents lung infection in non-human primates. bioRxiv 280818. https:// doi.org/10.1101/2020.09.08.280818

69. Pawlowski C, Lenehan P, Puranik A et al (2021) FDA-authorized mRNA COVID-19 vaccines are effective per real-world evidence synthesized across a multi-state health system. Med (N Y) 2:979992.e8. https://doi.org/10.1101/2021.02.15.21251623

70. Thompson MG, Burgess JL, Naleway AL et al (2021) Interim estimates of vaccine effectiveness of BNT162b2 and mRNA1273 COVID-19 vaccines in preventing SARS-CoV-2 infection among health care personnel, first responders, and other essential and frontline workers-eight US locations. MMWR Morb Mortal Wkly Rep 70:495-500. https://doi.org/10.15585/mmwr. $\mathrm{mm} 7013 \mathrm{e} 3$

71. Blain H, Tuaillon E, Gamon L et al (2021) Spike antibody levels of nursing home residents with or without prior COVID-19 3 weeks after a single BNT162b2 vaccine dose. JAMA. https:// doi.org/10.1001/jama.2021.6042

72. Scala E, Abeni D, Tedeschi A et al (2021) Atopic status protects from severe complications of COVID-19. Allergy 76:899-902. https://doi.org/10.1111/all.14551

73. Timberlake DT, Narayanan D, Ogbogu PU et al (2021) Severity of COVID-19 in hospitalized patients with and without atopic disease. World Allergy Organ J 14:100508. https://doi.org/10. 1016/j.waojou.2021.100508

74. Kimura H, Francisco D, Conway M et al (2020) Type 2 inflammation modulates ACE2 and TMPRSS2 in airway epithelial cells. J Allergy Clin Immunol 146:80-88.e8

75. Huang C, Wang Y, Li X et al (2020) Clinical features of patients infected with 2019 novel coronavirus in Wuhan, China. Lancet 395:497-506. https://doi.org/10.1016/S0140-6736(20)30183-5

76. Verity R, Okell LC, Dorigatti I et al (2020) Estimates of the severity of coronavirus disease 2019: a model-based analysis. Lancet Infect Dis 20:669-677. https://doi.org/10.1016/S1473-3099(20)30243-7

77. Wu JT, Leung K, Bushman M et al (2020) Estimating clinical severity of COVID-19 from the transmission dynamics in Wuhan, China. Nat Med 26:506-510. https://doi.org/10.1038/ s41591-020-0822-7

78. Li J, Huang DQ, Zou B et al (2021) Epidemiology of COVID-19: a systematic review and meta-analysis of clinical characteristics, risk factors, and outcomes. J Med Virol 93:1449-1458. https:// doi.org/10.1002/jmv.26424

79. Lippi G, Henry BM (2020) Chronic obstructive pulmonary disease is associated with severe coronavirus disease 2019 (COVID-19). Respir Med 167:105941. https://doi.org/10.1016/j.rmed.2020. 105941

80. Leung JM, Yang CX, Tam A et al (2020) ACE-2 expression in the small airway epithelia of smokers and COPD patients: implications for COVID-19. Eur Respir J 55. https://doi.org/10.1183/13993003. 00688-2020

81. Cheng DO, Hurst JR (2021) COVID-19 and 'basal' exacerbation frequency in COPD. Thorax 76:432-433. https://doi.org/10.1136/ thoraxjnl-2020-216637

82. Falagas ME, Mourtzoukou EG, Vardakas KZ (2007) Sex differences in the incidence and severity of respiratory tract infections. Respir Med 101:1845-1863. https://doi.org/10.1016/j.rmed. 2007.04.011

83. Gal-Oz ST, Maier B, Yoshida H et al (2019) ImmGen report: sexual dimorphism in the immune system transcriptome. Nat Commun 10:4295. https://doi.org/10.1038/s41467-019-12348-6

84. Cai Q, Huang D, Ou P et al (2020) COVID-19 in a designated infectious diseases hospital outside Hubei Province, China. Allergy 75:1742-1752. https://doi.org/10.1111/all.14309

85. Wang D, Hu B, Hu C et al (2020) Clinical characteristics of 138 hospitalized patients with 2019 novel coronavirus-infected pneumonia in Wuhan, China. JAMA 323:1061-1069. https://doi. org/10.1001/jama.2020.1585

86. Wan S, Xiang Y, Fang W et al (2020) Clinical features and treatment of COVID-19 patients in northeast Chongqing. J Med Virol 92:797-806. https://doi.org/10.1002/jmv.25783

87. Liang W, Guan W, Chen R et al (2020) Cancer patients in SARSCoV-2 infection: a nationwide analysis in China. Lancet Oncol 21:335-337. https://doi.org/10.1016/S1470-2045(20)30096-6

88. Wang L, Li X, Chen H et al (2020) Coronavirus disease 19 infection does not result in acute kidney injury: an analysis of 116 hospitalized patients from Wuhan, China. Am J Nephrol 51:343-348. https://doi.org/10.1159/000507471 
89. Bae S, Kim SR, Kim MN, Shim WJ, Park SM (2021) Impact of cardiovascular disease and risk factors on fatal outcomes in patients with COVID-19 according to age: a systematic review and meta-analysis. Heart 107:373-380. https://doi.org/10.1136/ heartjnl-2020-317901

90. Cai Q, Chen F, Wang T et al (2020) Obesity and COVID-19 severity in a designated hospital in Shenzhen, China. Diabetes Care 43:1392-1398. https://doi.org/10.2337/dc20-0576

91. Goyal P, Choi JJ, Pinheiro LC et al (2020) Clinical characteristics of Covid-19 in New York City. N Engl J Med 382:2372-2374. https://doi.org/10.1056/NEJMc2010419

92. Li B, Yang J, Zhao F et al (2020) Prevalence and impact of cardiovascular metabolic diseases on COVID-19 in China. Clin Res Cardiol 109:531-538. https://doi.org/10.1007/ s00392-020-01626-9

93. Sarzi-Puttini P, Giorgi V, Sirotti S et al (2020) COVID-19, cytokines and immunosuppression: what can we learn from severe acute respiratory syndrome? Clin Exp Rheumatol 38:337-342

94. Qin C, Zhou L, Hu Z et al (2020) Dysregulation of immune response in patients with coronavirus 2019 (COVID-19) in Wuhan, China. Clin Infect Dis 71:762-768. https://doi.org/10. 1093/cid/ciaa248

95. Ruan Q, Yang K, Wang W, Jiang L, Song J (2020) Clinical predictors of mortality due to COVID-19 based on an analysis of data of 150 patients from Wuhan, China. Intensive Care Med 46:846-848. https://doi.org/10.1007/s00134-020-05991-x

96. Zhang JJ, Dong X, Cao YY et al (2020) Clinical characteristics of 140 patients infected with SARS-CoV-2 in Wuhan, China. Allergy 75:1730-1741. https://doi.org/10.1111/all.14238

97. Zhang JJ, Cao YY, Tan G et al (2021) Clinical, radiological, and laboratory characteristics and risk factors for severity and mortality of 289 hospitalized COVID-19 patients. Allergy 76:533-550. https://doi.org/10.1111/all.14496

98. Lin J, Yan H, Chen $\mathrm{H}$ et al (2021) COVID-19 and coagulation dysfunction in adults: a systematic review and meta-analysis. J Med Virol 93:934-944. https://doi.org/10.1002/jmv.26346

99. Liu Y, Sun W, Guo Y et al (2020) Association between platelet parameters and mortality in coronavirus disease 2019: retrospective cohort study. Platelets 31:490-496. https://doi.org/10.1080/ 09537104.2020 .1754383

100. Guo W, Li M, Dong Y et al (2020) Diabetes is a risk factor for the progression and prognosis of COVID-19. Diabetes Metab Res Rev e3319. https://doi.org/10.1002/dmrr.3319

101. Chen Q, Zheng Z, Zhang C et al (2020) Clinical characteristics of 145 patients with corona virus disease 2019 (COVID-19) in Taizhou, Zhejiang, China. Infection 48:543-551. https://doi.org/ 10.1007/s15010-020-01432-5

102. Cron RQ (2020) Coronavirus is the trigger, but the immune response is deadly. Lancet Rheumatol 2:e370-e371. https://doi. org/10.1016/S2665-9913(20)30165-X

103. Magro C, Mulvey JJ, Berlin D et al (2020) Complement associated microvascular injury and thrombosis in the pathogenesis of severe COVID-19 infection: a report of five cases. Transl Res 220:1-13. https://doi.org/10.1016/j.trs1.2020.04.007

104. Diao B, Wang C, Tan Y et al (2020) Reduction and functional exhaustion of T cells in patients with coronavirus disease 2019 (COVID-19). Front Immunol 11:827. https://doi.org/10.3389/ fimmu.2020.00827

105. Blanco-Melo D, Nilsson-Payant BE, Liu WC et al (2020) Imbalanced host response to SARS-CoV-2 drives development of COVID-19. Cell 181:1036-1045.e9. https://doi.org/10.1016/j. cell.2020.04.026

106. Jamilloux Y, Henry T, Belot A et al (2020) Should we stimulate or suppress immune responses in COVID-19? Cytokine and anti-cytokine interventions Autoimmun Rev 19:102567. https:// doi.org/10.1016/j.autrev.2020.102567

107. Gao Q, Bao L, Mao H et al (2020) Development of an inactivated vaccine candidate for SARS-CoV-2. Science 369:77-81. https://doi.org/10.1126/science.abc1932

108. Mallapaty S (2021) China COVID vaccine reports mixed results-what does that mean for the pandemic. Nature. https:// doi.org/10.1038/d41586-021-00094-z

109. Baden LR, El Sahly HM, Essink B et al (2021) Efficacy and safety of the mRNA-1273 SARS-CoV-2 vaccine. N Engl J Med 384:403-416. https://doi.org/10.1056/NEJMoa2035389

110. Polack FP, Thomas SJ, Kitchin N et al (2020) Safety and efficacy of the BNT162b2 mRNA COVID-19 vaccine. N Engl J Med 383:2603-2615. https://doi.org/10.1056/NEJMoa2034577

111. Chen H, Mao Y, Duan Z et al (2021) Three cases of COVID-19 variant Delta with and without vaccination-Chengdu City, Sichuan Province. China CDC Wkly 3:544-546. https://doi. org/10.46234/ccdew2021.137

112. Krammer F (2020) SARS-CoV-2 vaccines in development. Nature 586:516-527. https://doi.org/10.1038/s41586-020-2798-3

113. Mishra SK, Tripathi T (2021) One year update on the COVID-19 pandemic: where are we now? Acta Trop 214:105778. https://doi. org/10.1016/j.actatropica.2020.105778

114. Fatima U, Rizvi SSA, Fatima S, Hassan MI (2020) Impact of hydroxychloroquine/chloroquine in COVID-19 therapy: two sides of the coin. J Interferon Cytokine Res 40:469-471. https:// doi.org/10.1089/jir.2020.0105

115. Funnell SGP, Dowling WE, Muñoz-Fontela C et al (2020) Emerging preclinical evidence does not support broad use of hydroxychloroquine in COVID-19 patients. Nat Commun 11:4253. https://doi. org/10.1038/s41467-020-17907-w

116. Singh B, Ryan H, Kredo T, Chaplin M, Fletcher T (2021) Chloroquine or hydroxychloroquine for prevention and treatment of COVID-19. Cochrane Database Syst Rev 2:CD013587. https:// doi.org/10.1002/14651858.CD013587.pub2

117. Cao B, Wang Y, Wen D et al (2020) A trial of lopinavir-ritonavir in adults hospitalized with severe COVID-19. N Engl J Med 382:1787-1799. https://doi.org/10.1056/NEJMoa2001282

118. Fan Z, Chen L, Li J et al (2020) Clinical features of COVID19-related liver functional abnormality. Clin Gastroenterol Hepatol 18:1561-1566. https://doi.org/10.1016/j.cgh.2020.04.002

119. Lim J, Jeon S, Shin HY et al (2020) Case of the index patient who caused tertiary transmission of COVID-19 infection in Korea: the application of lopinavir/ritonavir for the treatment of COVID-19 infected pneumonia monitored by quantitative RT-PCR. J Korean Med Sci 35:e79. https://doi.org/10.3346/jkms.2020.35.e79

120. Beigel JH, Tomashek KM, Dodd LE et al (2020) Remdesivir for the treatment of COVID-19-final report. Report N Engl J Med 383:1813-1826. https://doi.org/10.1056/NEJMoa2007764

121. WHO Solidarity Trial Consortium, Pan H, Peto R et al (2021) Repurposed antiviral drugs for COVID-19-interim WHO solidarity trial results. N Engl J Med 384:497-511

122. Wang Y, Zhang D, Du G et al (2020) Remdesivir in adults with severe COVID-19: a randomised, double-blind, placebo-controlled, multicentre trial. Lancet 395:1569-1578

123. Ghosn L, Chaimani A, Evrenoglou T et al (2021) Interleukin-6 blocking agents for treating COVID-19: a living systematic review. Cochrane Database Syst Rev 3:CD013881. https://doi. org/10.1002/14651858.CD013881

124. Juul S, Nielsen EE, Feinberg J et al (2021) Interventions for treatment of COVID-19: 2nd edition of a living systematic review with meta-analyses and trial sequential analyses (the LIVING Project). PLoS One 16:e0248132. https://doi.org/10.1371/journal.pone. 0248132 
125. Hu L, Chen S, Fu Y et al (2020) Risk factors associated with clinical outcomes in 323 coronavirus disease 2019 (COVID-19) hospitalized patients in Wuhan, China. Clin Infect Dis 71:20892098. https://doi.org/10.1093/cid/ciaa539

126. Shaker MS, Oppenheimer J, Grayson M et al (2020) COVID-19: pandemic contingency planning for the allergy and immunology clinic. J Allergy Clin Immunol Pract 8:1477-1488.e5. https://doi. org/10.1016/j.jaip.2020.03.012

127. Johnston SL (2020) Asthma and COVID-19: is asthma a risk factor for severe outcomes? Allergy 75:1543-1545. https://doi. org/10.1111/all.14348

128. Caminati M, Lombardi C, Micheletto C et al (2020) Asthmatic patients in COVID-19 outbreak: few cases despite many cases. J Allergy Clin Immunol 146:541-542. https://doi.org/10.1016/j. jaci.2020.05.049

129. Garg S, Kim L, Whitaker M et al (2020) Hospitalization rates and characteristics of patients hospitalized with laboratoryconfirmed coronavirus disease 2019-COVID-NET, 14 states, 1-30 Mar 2020. MMWR Morb Mortal Wkly Rep 69:458-464. https://doi.org/10.15585/mmwr.mm6915e3

130. To T, Viegi G, Cruz A et al (2020) A global respiratory perspective on the COVID-19 pandemic: commentary and action proposals. Eur Respir J 56. https://doi.org/10.1183/13993003. 01704-2020

131. Zhu Z, Hasegawa K, Ma B, Fujiogi M, Camargo CA Jr, Liang L (2020) Association of asthma and its genetic predisposition with the risk of severe COVID-19. J Allergy Clin Immunol 146:327329.e4. https://doi.org/10.1016/j.jaci.2020.06.001

132. Green I, Merzon E, Vinker S, Golan-Cohen A, Magen E (2021) COVID-19 susceptibility in bronchial asthma. J Allergy Clin Immunol Pract 9:684-692.e1. https://doi.org/10.1016/j.jaip.2020. 11.020

133. Caminati M, Vultaggio A, Matucci A et al (2021) Asthma in a large COVID-19 cohort: prevalence, features, and determinants of COVID-19 disease severity. Respir Med 176:106261. https:// doi.org/10.1016/j.rmed.2020.106261

134. Mendes NF, Jara CP, Mansour E, Araújo EP, Velloso LA (2021) Asthma and COVID-19: a systematic review. Allergy Asthma Clin Immunol 17:5. https://doi.org/10.1186/s13223-020-00509-y

135. World Health Organization (WHO) (2020) Chronic respiratory diseases: asthma. https://www.who.int/news-room/q-a-detail/ chronic-respiratory-diseases-asthma. Accessed $31^{\text {st }}$ Oct 2021

136. Ritchie AI, Jackson DJ, Edwards MR, Johnston SL (2016) Airway epithelial orchestration of innate immune function in response to virus infection. A focus on asthma. Ann Am Thorac Soc 13 Suppl 1:S55-S63. https://doi.org/10.1513/AnnalsATS. 201507-421MG

137. Yang JM, Koh HY, Moon SY et al (2020) Allergic disorders and susceptibility to and severity of COVID-19: a nationwide cohort study. J Allergy Clin Immunol 146:790-798. https://doi.org/10. 1016/j.jaci.2020.08.008

138. Radzikowska U, Ding M, Tan G et al (2020) Distribution of ACE2, CD147, CD26, and other SARS-CoV-2 associated molecules in tissues and immune cells in health and in asthma, COPD, obesity, hypertension, and COVID-19 risk factors. Allergy 75:2829-2845. https://doi.org/10.1111/all.14429

139. Sajuthi SP, DeFord P, Jackson ND et al (2020) Type 2 and interferon inflammation strongly regulate SARS-CoV-2 related gene expression in the airway epithelium. bioRxiv 034454. https://doi. org/10.1101/2020.04.09.034454

140. Song J, Zeng M, Wang $\mathrm{H}$ et al (2021) Distinct effects of asthma and COPD comorbidity on disease expression and outcome in patients with COVID-19. Allergy 76:483-496. https://doi.org/ 10.1111/all.14517

141. Ziegler CGK, Allon SJ, Nyquist SK et al (2020) SARS-CoV-2 receptor ACE2 is an interferon-stimulated gene in human airway epithelial cells and is detected in specific cell subsets across tissues. Cell 181:1016-1035.e19. https://doi.org/10. 1016/j.cell.2020.04.035

142. Carli G, Cecchi L, Stebbing J, Parronchi P, Farsi A (2021) Is asthma protective against COVID-19? Allergy 76:866-868. https://doi.org/10.1111/all.14426

143. Halpin DMG, Singh D, Hadfield RM (2020) Inhaled corticosteroids and COVID-19: a systematic review and clinical perspective. Eur Respir J 55. https://doi.org/10.1183/13993003. 01009-2020

144. Halpin DMG, Faner R, Sibila O, Badia JR, Agusti A (2020) Do chronic respiratory diseases or their treatment affect the risk of SARS-CoV-2 infection? Lancet Respir Med 8:436-438. https:// doi.org/10.1016/S2213-2600(20)30167-3

145. Peters MC, Sajuthi S, Deford P et al (2020) COVID-19-related genes in sputum cells in asthma. Relationship to demographic features and corticosteroids. Am J Respir Crit Care Med 202:8390. https://doi.org/10.1164/rccm.202003-08210C

146. Hoffmann M, Kleine-Weber H, Schroeder S et al (2020) SARSCoV-2 cell entry depends on ACE2 and TMPRSS2 and is blocked by a clinically proven protease inhibitor. Cell 181:271280.e8. https://doi.org/10.1016/j.cell.2020.02.052

147. Gill MA, Liu AH, Calatroni A et al (2018) Enhanced plasmacytoid dendritic cell antiviral responses after omalizumab. J Allergy Clin Immunol 141:1735-1743.e9. https://doi.org/10.1016/j.jaci. 2017.07.035

148. Lommatzsch M, Stoll P, Virchow JC (2020) COVID-19 in a patient with severe asthma treated with omalizumab. Allergy 75:2705-2708. https://doi.org/10.1111/all.14456

149. Ludvigsson JF (2020) Systematic review of COVID-19 in children shows milder cases and a better prognosis than adults. Acta Paediatr 109:1088-1095. https://doi.org/10.1111/apa.15270

150. Yonker LM, Neilan AM, Bartsch Y et al (2020) Pediatric severe acute respiratory syndrome coronavirus 2 (SARS-CoV-2): clinical presentation, infectivity, and immune responses. J Pediatr 227:45-52.e5. https://doi.org/10.1016/j.jpeds.2020.08.037

151. Bunyavanich S, Do A, Vicencio A (2020) Nasal gene expression of angiotensin-converting enzyme 2 in children and adults. JAMA 323:2427-2429. https://doi.org/10.1001/jama.2020.8707

152. Liu Y, Yan LM, Wan L et al (2020) Viral dynamics in mild and severe cases of COVID-19. Lancet Infect Dis 20:656-657. https://doi.org/10.1016/S1473-3099(20)30232-2

153. Yang J, Zheng Y, Gou X et al (2020) Prevalence of comorbidities and its effects in patients infected with SARS-CoV-2: a systematic review and meta-analysis. Int J Infect Dis 94:91-95. https:// doi.org/10.1016/j.ijid.2020.03.017

154. Götzinger F, Santiago-García B, Noguera-Julián A et al (2020) COVID-19 in children and adolescents in Europe: a multinational, multicentre cohort study. Lancet Child Adolesc Health 4:653-661. https://doi.org/10.1016/S2352-4642(20)30177-2

155. DeBiasi RL, Song X, Delaney M et al (2020) Severe coronavirus disease-2019 in children and young adults in the Washington, DC, metropolitan region. J Pediatr 223:199-203.e1. https://doi. org/10.1016/j.jpeds.2020.05.007

156. Swann OV, Holden KA, Turtle L et al (2020) Clinical characteristics of children and young people admitted to hospital with COVID-19 in United Kingdom: prospective multicentre observational cohort study. BMJ 370:m3249. https://doi.org/ 10.1136/bmj.m3249

157. Kara AA, Böncüoğlu E, Kiymet E et al (2021) Evaluation of predictors of severe-moderate COVID-19 infections at children: a review of 292 children. J Med Virol 93:6634-6640. https://doi. org/10.1002/jmv.27237

158. Ouldali N, Yang DD, Madhi F et al (2021) Factors associated with severe SARS-CoV-2 infection. Pediatrics 147. https://doi. org/10.1542/peds.2020-023432 
159. Antoon JW, Grijalva CG, Thurm C et al (2021) Factors associated with COVID-19 disease severity in US children and adolescents. J Hosp Med 16:603-610. https://doi.org/10.12788/jhm.3689

160. Zheng F, Liao C, Fan QH et al (2020) Clinical characteristics of children with coronavirus disease 2019 in Hubei. China Curr Med Sci 40:275-280. https://doi.org/10.1007/ s11596-020-2172-6

161. Tagarro A, Epalza C, Santos M et al (2020) Screening and severity of coronavirus disease 2019 (COVID-19) in children in Madrid. JAMA Pediatr, Spain. https://doi.org/10.1001/ jamapediatrics.2020.1346

162. González-García N, Castilla-Peón MF, Solórzano Santos F et al (2021) COVID-19 incidence and mortality by age strata and comorbidities in Mexico City: a focus in the pediatric population. Front Public Health 9:738423. https://doi.org/10.3389/ fpubh.2021.738423

163. Floyd GC, Dudley JW, Xiao R et al (2021) Prevalence of asthma in hospitalized and non-hospitalized children with COVID-19. J Allergy Clin Immunol Pract 9:2077-2079.e2. https://doi.org/10. 1016/j.jaip.2021.02.038

164. Qiu H, Wu J, Hong L, Luo Y, Song Q, Chen D (2020) Clinical and epidemiological features of 36 children with coronavirus disease 2019 (COVID-19) in Zhejiang, China: an observational cohort study. Lancet Infect Dis 20:689-696. https://doi.org/10. 1016/S1473-3099(20)30198-5

165. Sun D, Li H, Lu XX et al (2020) Clinical features of severe pediatric patients with coronavirus disease 2019 in Wuhan: a single center's observational study. World J Pediatr 16:251-259. https:// doi.org/10.1007/s12519-020-00354-4

166. Chao JY, Derespina KR, Herold BC et al (2020) Clinical characteristics and outcomes of hospitalized and critically ill children and adolescents with coronavirus disease 2019 at a tertiary care medical center in New York City. J Pediatr 223:14-19.e2. https:// doi.org/10.1016/j.jpeds.2020.05.006

167. Zhou MY, Xie XL, Peng YG et al (2020) From SARS to COVID19: what we have learned about children infected with COVID19. Int J Infect Dis 96:710-714. https://doi.org/10.1016/j.ijid. 2020.04.090

Publisher's Note Springer Nature remains neutral with regard to jurisdictional claims in published maps and institutional affiliations. 